\title{
A EMENDA CONSTITUCIONAL NO. 54 E O RESGATE DA CIDADANIA BRASILEIRA PARA FILHOS DE NACIONAIS NASCIDOS NO ESTRANGEIRO*
}

\author{
Florisbal de SOUZA DEL'OLMO**
}

\begin{abstract}
RESUMEN: Este trabajo se refiere a la enmienda constitucional núm. 54 del 20 de septiembre de 2007. La cual reestablece en nuestro sistema legal, el reconocimiento de la nacionalidad brasileña originaria a través del registro de niños brasileños nacidos fuera de Brasil en los consulados y embajadas de otros países. Este reconocimiento y el criterio para su concesión como lo determina el derecho internacional, son analizados en este trabajo. Adicionalmente se hace una consideración de los últimos cambios hechos a la Constitución, los cuales permiten que cambie la situación de miles de niños reclamando su ciudadanía.
\end{abstract}

ABSTRACT: This work addresses the Constitutional Amendment number 54 from September 20th, 2007. This amendment re-established the recognition of the original Brazilian nationality in our Legal System, by registry on the Brazilian Consulate and Embassy in other countries, of Brazilian child born outside of Brazil. This recognition and the criteria for its concession as admitted by International Law are analyzed in this paper. Additionally the non-nationality as considered in the latest changes done to the Constitution; this allows the change of the situation of thousands of children reclaiming their citizenship.

RÉSUMÉ: Cet travail est referant à la reforme constitutionnel no. 54 du septembre 20, 2007 laquelle rétabli dans notre system légal, le reconnaissance de la nationalité brésilien originaire au travers des registre des enfants brésilien née à l extérieur du Brésil dans les consulat ou ambassade d'autres pays. Cet reconnaissance et le critère pour ça concession comment est déterminé par le Droit International sont analyses dans cet travail. En addition c'est fait un considération des dernier changement fait a la constitution lesquelles permit le changement de la situation des miles des enfants qui demande ça nationalité.

* Artículo recibido el 25 de marzo de 2008 y aceptado para su publicación el 20 de mayo de 2008.

** Mestre (UFSC) e doutor em direito (UFRGS), com estágio pós-doutoral em direito pela UFSC. Professor na graduação e no curso de mestrado em direito da URI, Santo Ângelo, RS. Professor convidado da UFAM, Manaus, AM, e da UFRGS. Membro da Sociedade Brasileira de Direito Internacional. 
SUMÁRIO: I. Considerações iniciais. II. O instituto da nacionalidade. III. A anacionalidade. IV. Considerações finais. V. Referências.

\section{CONSIDERAÇÕES INICIAIS}

Aborda este estudo a Emenda Constitucional no. 54, de 20 de setembro de 2007, que reintroduz no ordenamento jurídico brasileiro o reconhecimento da nacionalidade pelo registro de nascimento em repartições consulares ou diplomáticas do país no exterior, que havia sido suprimido em emenda anterior, de 1994.

Será dividido em duas partes, ocupando-se a primeira do instituto da nacionalidade, detendo-se nos critérios de atribuição da mesma admitidos pelo direito internacional, o jus soli e o jus sanguinis. A segunda parte abordará a anacionalidade, instituto mais conhecido como apatridia, tecendo reflexões sobre a presença do sistema do jus sanguinis na legislação brasileira e as dificuldades enfrentadas por filhos de brasileiros nascidos em outros países, assim como a bem-vinda Emenda Constitucional no. 54, que possibilita a integração na comunidade brasileira dessas crianças, assegurando a elas todos os direitos da nossa cidadania.

\section{O INSTITUTO DA NACIONALIDADE}

Apresenta-se a nacionalidade como requisito basilar para o reconhecimento da cidadania. Daí a relevância e atualidade de seu estudo, que se espraia por vários segmentos do mundo das ciências jurídicas, dentre os quais o direito internacional público, o direito internacional privado, o direito constitucional, o direito civil e o direito processual civil.

\section{Observações preliminares}

Dispõem os países de ampla liberdade para conferir sua nacionalidade, levando em consideração seus valores sociais e culturais. O exercício dessa prerrogativa, contudo, necessita estar consentâneo com os princípios e costumes do direito internacional, sem o que essa atribuição não seria reconhecida pelos demais estados. Não pode, assim, o estado instituir uma legislação alicerçada em seu próprio interesse, pois isso iria dificultar as relações do mesmo com outros países e criar dificuldades a 
essas pessoas. Nesse contexto, são pertinentes essas observações de Ferrante:

As idéias dominantes em cada período da história da humanidade impregnaram, sem dúvida, a conceituação da nacionalidade, mas não lhe atingiram o fundamento básico, conformado a razões de ordem jurídica, que permanecem inalteráveis, e traduzidas na necessidade de cada Estado, em todos os tempos, de indicar seus próprios nacionais. ${ }^{1}$

Pode-se afirmar que o direito internacional confia ao estado, em princípio, a competência da normatização da aquisição e perda da sua nacionalidade, prescrevendo as necessárias limitações, com o que impede, por exemplo, a supressão da categoria de estrangeiros pela concessão irrestrita e indiscriminada da nacionalidade.

A nacionalidade identifica o vínculo jurídico fundamental entre o ser humano e o Estado, constituindo-se no elo que cria, para ambos, direitos e obrigações recíprocos, que os manterão unidos, mesmo na eventualidade de afastamento daquele do espaço geográfico desse, onde continuará a contar com sua proteção e a prestar respeito às diretrizes emanantes da soberania estatal. Esse vínculo, além de jurídico-político, é também social e moral entre o Estado soberano e cada uma das pessoas físicas que a ele estão ligadas, constituindo estas a dimensão pessoal daquele por liames que o próprio estado institui, observando os parâmetros do direito internacional.

Convém referir que cidadania e nacionalidade, embora institutos distintos, são complementares, fundados em uma solidariedade de interesses e de sentimentos. Ambas se ocupam da pessoa física, do homem, que constitui a sociedade humana, organizada juridicamente em Estado, que é o sujeito original e necessário do direito internacional.

1 Ferrante, Miguel Jeronymo, Nacionalidade: brasileiros natos e naturalizados, 2 ed., São Paulo, Saraiva, 1984, p. 16. Complementa o mesmo autor: "Como quer que seja, é salutar que as legislações, visando os interesses dos Estados, não se apartem das regras do direito internacional. A convivência internacional, que um mundo em transformação torna cada dia mais premente, já não admite ignorar a existência dos interesses de outras nações. E não se pode negar que, inobstante a inexistência de um direito internacional positivo sobre a nacionalidade, há uma tendência cada vez mais sensível de submeter-se a ação legislativa do estado, nesse particular, aos princípios que a comunhão internacional impõe". Ibidem, p. 29. 
2. $O$ jus soli

A ordem jurídica internacional admite dois critérios para normatizar a concessão da nacionalidade de origem, a primária, aquela a que a pessoa se vê investida ao nascer. São o jus sanguinis e o jus soli. Ambos têm o nascimento do ser humano como pressuposto basilar para essa atribuição, tendo o jus sanguinis surgido primeiro, ainda na antigüidade.

Consiste o sistema do jus soli na concessão da nacionalidade em função do local de nascimento, literalmente direito do solo, sem considerar, por conseguinte, a condição nacional dos pais. Sua base se assenta no fato de que quem nasce no território do Estado, desse Estado é nacional. É o chamado critério territorial.

Entende-se que o jus soli surgiu, ou pelo menos se consagrou, no período feudal, no qual a idéia dominante era manter o indivíduo preso à terra. Admite-se hoje, contudo, seu sentido democrático, uma vez que não discrimina parcelas da população que seriam consideradas estrangeiras pelo simples fato de seus pais não serem oriundos do Estado.

É o critério de eleição dos estados novos ou em fase de desenvolvimento, onde impera a necessidade de formação de uma população nacional. Daí ser o princípio adotado pelos países do continente americano. Quando surge um estado seria até inconcebível a adoção do jus sanguinis, pois é muito reduzido, nessa fase inicial, o número de nacionais. Também os países que recebem muitos imigrantes costumam adotar o jus soli, com o que propiciam a integração dos descendentes na vida nacional.

É oportuno observar que o movimento migratório existe desde os primórdios da humanidade, gerando conseqüências nos mais diversos setores. Ocasionada por fatores distintos, entre eles o econômico, o político, o social e o cultural, a migração atingiu proporções consideráveis com a globalização e com o aperfeiçoamento dos meios de comunicação e de transporte. Nesta primeira década do século XXI, grande número de seres humanos, provenientes dos países em estágio menos avançado de desenvolvimento, inclusive do Brasil, deslocam-se em direção dos Estados mais ricos e industrializados.

Observa Paul de La Pradelle que, com a aplicação do jus sanguinis, a influência da família é preponderante na primeira geração, deixando de ser na segunda e desaparece totalmente na terceira geração. Sugere, então, para uma legislação moderna, uma destas combinações: dar à criança 
a nacionalidade de seus pais, com a faculdade de opção da nacionalidade do lugar de nascimento na maioridade; ou conceder a nacionalidade do lugar do nascimento, com a faculdade de opção da nacionalidade de qualquer dos pais, quando atingir a maioridade. ${ }^{2}$

O emprego predominante do jus soli, com concessões, necessárias e pertinentes, ao jus sanguinis, em um oportuno sistema misto, parece ser o caminho que se traça para o futuro da nacionalidade nata.

Sopesando os fatores positivos e negativos do jus soli e do jus sanguinis, Dardeau de Carvalho concluiu que o princípio da territorialidade, o jus soli, é mais lógico do que o sistema da filiação, o jus sanguinis. Entende que isso ocorre porque o ser humano é produto quase exclusivo do meio em que vive e, mais do que o sangue, é a terra, o ambiente que o cerca, e o fator determinante das suas inclinações, afeições e modos de agir e reagir contra os estímulos externos: "É o determinismo telúrico, afeiçoando-o, inexoravelmente, ao seu 'habitat". Complementa o saudoso estudioso: "Na luta entre os caracteres étnicos, raciais, consangüíneos, e o meio físico, a vitória cabe sempre ao último destes elementos. A influência do meio, sem dúvida, é muito mais poderosa do que os impulsos da estirpe sangüínea, quase sempre obliterada pela passagem de muitas gerações". ${ }^{3}$

Diante dos inconvenientes apontados pela doutrina no emprego absoluto do jus soli ou do jus sanguinis, é oportuno lembrar o outro extremo, como ocorre em São Tomé e Príncipe, pequena república de fala portuguesa na costa ocidental africana, que adota de forma absoluta os dois sistemas, em um único e sintético artigo de sua Constituição de 1990: “Artigo 3: São cidadãos santomenses todos os nascidos em território nacional, os filhos de pai ou mãe santomense e aqueles que como tal sejam considerados por Lei". ${ }^{4}$

O emprego do jus soli na atribuição da nacionalidade originária tem sido uma constante no ordenamento jurídico brasileiro, embora jamais de forma absoluta. Sempre ficou excluído da nacionalidade brasileira o ser humano que, mesmo tendo nascido no país, fosse filho de estrangeiro

2 Akzin, Mm. B. et al., La Nacionalité dans la Science Sociale et dans le Droit Contemporain, París, Librairie du Recueil Sirey, 1933, p. 216.

3 Dardeau de Carvalho, A., Nacionalidade e cidadania, Rio de Janeiro, Freitas Bastos, 1956, p. 16.

4 Gouveia, Jorge Bacelar (Introdução), As Constituições dos Estados lusófonos, Lisboa, Aequitas, 1993, p. 286. 
que estivesse no Brasil a serviço de sua pátria. Em essência, o conteúdo do dispositivo constitucional não mudou nas sucessivas Cartas Magnas que o país adotou, até a atual (1988), que considera brasileiros natos, conforme a alínea $a$ do inciso I do art. 12, "os nascidos na República Federativa do Brasil, ainda que de pais estrangeiros, desde que estes não estejam a serviço de seu país" (grifo acrescido).

\section{3. $O$ jus sanguinis}

O princípio de atribuição da nacionalidade pelo jus sanguinis reinou quase absoluto na maior parte da história, estando ainda presente em muitos países. Prevalece entre os estados mais populosos, como sói acontecer com os povos europeus. É que nesses países a tendência maior era de saída de parcelas da população, na busca em outras terras de oportunidades de realização pessoal e crescimento no campo material, condições inexistentes, muitas vezes, em seu estado. Tal fato ocorreu com certa freqüência, bastando lembrar as levas de italianos, alemães e japoneses que nos séculos XIX e XX se deslocaram de suas pátrias, buscando uma vida melhor no continente americano, inclusive no Brasil. Embora essa situação seja atualmente diversa, pelo período de prosperidade vivido pelos Estados de onde provieram esses imigrantes, permanece em suas ordens jurídicas o jus sanguinis como o critério de atribuição da nacionalidade.

Com a emigração tende a diminuir o número dos nacionais residentes no país e o emprego do jus sanguinis no ordenamento jurídico desses estados vai propiciar que os descendentes, nascidos nas novas terras, continuem ligados pela nacionalidade à pátria de seus genitores, aonde ao chegarem estarão capacitados para uma integração mais fácil.

Por isso, o jus sanguinis é o critério admitido, existindo países, como a Itália, que nem mesmo restringe as gerações de descendentes tidos como nacionais. As ordens jurídicas, em sua maioria, limitam aos filhos o reconhecimento da nacionalidade originária pelo jus sanguinis. É o que ocorre com Alemanha, França e Portugal, por exemplo, em cujas legislações não se reconhece, diretamente, como nacional o neto da pessoa que emigrou.

É oportuno destacar serem raros atualmente os casos de Estado que adota o jus sanguinis de forma absoluta. Seja reconhecendo como nacional a pessoa abandonada no território do Estado, atribuindo a condição 
ao filho de pais desconhecidos aí nascido ou concedendo a nacionalidade ao filho de estrangeiro, que já tenha, esse filho, nascido no país - que, em contrário, seria estrangeiro de segunda geração, sem abandonar o país que lhe nega a nacionalidade- o estado do jus sanguinis está reconhecendo os benefícios do jus soli, não permitindo que, em seu território, vivam na condição de anacionais (indivíduos não detentores da prerrogativa fundamental da nacionalidade por qualquer estado, mais conhecidos por apátridas), pessoas plenamente integradas na comunhão nacional, com domínio do idioma e adaptadas aos costumes e às tradições do país. Trata-se, como se pode observar, de louvável aceitação do sistema misto de atribuição da nacionalidade originária, no qual há concessões aos dois sistemas.

\section{A ANACIONALIDADE}

O emprego pelos países dos critérios de atribuição da nacionalidade originária estudados gera, muitas vezes, anomalias com conflitos positivo ou negativo, conhecidos na doutrina por plurinacionalidade ou apatridia. São bastante comuns atualmente os casos de dupla nacionalidade, que ocorrem quando uma criança nascida em país que adota o jus soli é filha de pais estrangeiros, nacionais de estado que admite o jus sanguinis.

Interessa-nos, neste momento, o outro instituto mencionado. Os seres humanos que nascem privados de nacionalidade ou que a perdem em qualquer fase da vida, conhecidos por apátridas, são pessoas nacionalmente desprotegidas. O termo apatridia tem sido o de eleição para a identificação da ausência de nacionalidade, usado pela doutrina e nos tratados internacionais que regem a matéria. Ilmar Penna Marinho fala das dificuldades dessas pessoas, afirmando que a situação delas é "particularmente precária, bem mais difícil do que a dos estrangeiros, porquanto estes últimos, se expulsos, serão sempre recebidos pelo Estado do qual possuem a nacionalidade". 5

Permite-se enfatizar que seria mais adequada a utilização de anacionalidade, pelo acréscimo do prefixo grego $a$, an, indicativo de negação, privação, ausência (sem) à palavra nacionalidade. Justifica-se esse ter-

5 Penna Marinho, Ilmar, Tratado sobre a nacionalidade, Rio de Janeiro, Departamento de Imprensa Nacional, 1956, vol. I, p. 33. 
mo por opor-se a nacionalidade, designativo do instituto, em oposição a apatridia, que contraria, na verdade, a idéia de patridia, termo que não se emprega em lugar de nacionalidade. ${ }^{6}$

Ao sugerir o emprego de anacionalidade para designar o instituto, pensa-se estar sendo coerente com o entendimento esposado por Penna Marinho, quando, em sua obra clássica sobre a nacionalidade, ao abordar a apatridia - que prefere chamar de apatrídia - lembra que "todo homem nasceu em algum lugar ou sofreu influência direta de algum fenômeno sociológico, como a religião, o meio geográfico, a língua, etc.", tendo em conseqüência uma pátria: "O que há são indivíduos sem nacionalidade, sem uma subordinação política", acentua o especialista. ${ }^{7}$

O termo apatridia, embora largamente usado, porta forte viés estigmatizante, dando uma conotação de supressão do vínculo do ser humano com sua pátria, reportando à lembrança a tragédia representada pelos Estados totalitários que privaram da nacionalidade seus cidadãos, como a Alemanha nazista, especialmente quanto aos judeus, e a Rússia comunista, aos dissidentes políticos, em geral, durante a longa e sanguinária ditadura de Stalin.

Designar por anacional o cidadão privado de nacionalidade, por ser um termo menos contundente e mais brando do que apátrida, oferece conotação de transitoriedade a essa situação e leva ao entendimento de que a condição de anacional será passageira, pela inserção dessa pessoa entre os nacionais de um estado, na esteira de movimentos humanitários, doutrinários e convencionais que buscam a supressão da anacionalidade, ou pelo menos a gradativa diminuição do número de pessoas por ela atingidas.

Por outro lado, verifica-se que o nefasto instituto da aligeância perpétua, resquício e triste contribuição do sistema feudal, desapareceu do mundo jurídico. Por essa prática medieval, havia uma subordinação perpétua do indivíduo, que estava obrigado a permanecer toda a vida ligado à terra, impedido de perder ou mudar de nacionalidade, liberando-se dessa fidelidade apenas com a autorização do soberano. Tal sujeição per-

6 Véase nossa dissertação de Mestrado em Direito (Universidade Federal de Santa Catarina), publicada pela Editora Forense, sob o título O Mercosul e a nacionalidade: estudo à luz do direito internacional, em 2001, pp. 68-75.

7 Penna Marinho, Ilmar, Tratado sobre a nacionalidade, Rio de Janeiro, Departamento de Imprensa Nacional, 1956, vol. IV, p. 246. 
durou na Grã-Bretanha até 1870 e na Rússia durante o período czarista. ${ }^{8}$ Não havia, pois, a liberdade de substituição de uma nacionalidade por outra, mesmo que essa fosse a vontade da pessoa. Nesse sentido - $\mathrm{e}$ apenas nele - a anacionalidade pode apresentar-se como algo menos negativo, pois é indicativa de liberdade e manifestação da vontade individual.

A principal fonte da anacionalidade está na existência dos dois sistemas utilizados pelos Estados na atribuição originária da nacionalidade. Assim, uma criança que nasce em país que adota o jus sanguinis, sendo seus pais oriundos de estado que privilegia o jus soli, não terá nacionalidade. E essas situações ocorrem com freqüência. Outra fonte é a legislação de países totalitários prescrevendo a perda da nacionalidade por motivos políticos ou raciais.

Em realidade, o anacional é visto como estrangeiro pelo estado em que se encontra, não merecendo, rotineiramente, proteção diplomática. Permanece na dependência de que leis locais o amparem.

Afortunadamente, esse amparo começa a ganhar espaço na legislação de alguns países, sendo digna de registro a Constituição de Portugal, de 25 de abril de 1976, que em seu artigo 15 prescreve: "Os estrangeiros e os apátridas que se encontrem ou residam em Portugal gozam dos direitos e estão sujeitos aos deveres do cidadão português".

$\mathrm{O}$ fim da anacionalidade tem sido buscado pelas organizações internacionais e pelos Estados, contribuindo para diminuir o número de pessoas nessa situação. Por vezes, contudo, o próprio homem pode ser o causador de sua apatridia, quando renuncia de forma espontânea à nacionalidade e não demonstra interesse em adquirir outra, o que, felizmente, não é freqüente. A Declaração Universal dos Direitos Humanos assegura, no artigo 15, que "toda pessoa tem direito a uma nacionalidade". O mais importante documento internacional sobre o tema é a Convenção para a Redução dos Casos de Apatridia, assinada em Nova Iorque, no dia 30 de agosto de 1961.

8 Faro Junior, Luiz P. F. de, Direito internacional público, 4 ed., Rio de Janeiro, Borsoi, 1965, p. 169. 
1. Os limites do jus sanguinis privam a nacionalidade de filhos de brasileiros

Os parâmetros da nacionalidade na ordem jurídica brasileira sempre emanaram do texto constitucional e centraram-se no critério do jus soli. Essa primazia, porém, do local de nascimento para estabelecer a nacionalidade brasileira não é absoluta, pois já na Constituição de 1824 (artigo 6) eram considerados cidadãos brasileiros os filhos de pai brasileiro (e os ilegítimos de mãe brasileira) nascidos no estrangeiro, desde que viessem a estabelecer domicílio no Império. Evidente concessão ao critério do jus sanguinis, que se mantém no ordenamento jurídico do país até hoje. Encontra-se aí a faculdade de ser reconhecido brasileiro alguém que não nasceu no país, excepcionando o jus soli, mas condicionando a investidura à presença de outros fatores. Aos filhos de brasileiro nascidos no exterior com o pai a serviço do Brasil, por exemplo, era assegurado esse direito desde então.

Além desses casos, a guarida ao jus sanguinis na ordem jurídica brasileira se condiciona à fixação de residência no Brasil associada à opção pela nossa nacionalidade. Nesse contexto, poderá ser brasileira a pessoa nascida no estrangeiro e que lá tenha vivido a maior parte de sua existência, mesmo afastada das tradições brasileiras e até sem falar português, desde que um de seus pais, pelo menos, seja brasileiro, e em qualquer época de sua vida fixe residência no Brasil e opte pela nacionalidade brasileira. Será brasileira nata, pois, embora não exercido anteriormente, ela tinha o direito potencial de se ver reconhecida brasileira, condição que estava adormecida na expectativa do adimplemento da opção.

Como se verá no item seguinte, a concessão da nacionalidade aos filhos de brasileiro que nascem — esses filhos — em outro país, somente quando algum dos genitores lá se encontra a serviço do Brasil ou quando esse filho estabelece residência em nosso país e opta pela nacionalidade brasileira, vinha condenando à anacionalidade grande número de crianças unidas por laços familiares e afetivos ao Brasil.

\section{A Emenda Constitucional no. 54 e o registro consular}

A atribuição da nacionalidade pelo registro de nascimento em repartições consulares ou diplomáticas do Brasil no exterior foi introduzida na nossa ordem jurídica pela Constituição de 15 de março de 1967 (artigo 140), merecendo logo aprovação de boa parte da doutrina e da juris- 
prudência, até porque tais organismos do país, situados no estrangeiro, têm, entre seus objetivos, mormente os consulados, o de efetuar registros de nascimentos, casamentos e óbitos de nacionais. Jacob Dolinger denominou-a aquisição jus sanguinis mais registro. ${ }^{9}$

A adoção pela Lex Legum da nacionalidade originária, mediante registro em repartição brasileira situada em outro país, determina a atribuição da nacionalidade, de per si, imediatamente. O status de brasileiro nato deixa de ser um direito potencial da pessoa, nessa situação, para se tornar um fato real: ela é brasileira, detentora de todos os direitos que lhe são inerentes, sem precisar adimplir qualquer outra condição, como domicílio no país ou opção pela nacionalidade, em tal ou qual época. Ela se torna brasileira, independente de que venha ou não estabelecer-se no Brasil. O não-registro na repartição no exterior, sim, continua a implicar na necessidade de esse ser humano vir residir no Brasil e optar pela nacionalidade brasileira.

Incompreensivelmente, entretanto, a Emenda Constitucional de Revisão no. 3, de 07 de junho de 1994, que alterou o artigo 12, da Carta Magna de 1988, em alguns pontos, retirara esse dispositivo, deixando de constar o registro na repartição brasileira no exterior. Essa supressão vinha merecendo críticas, acreditando-se até que a intenção do revisor não tenha sido a de afastar tal forma de atribuição da nacionalidade originária. Wilba Bernardes a via como um equívoco, consolidando "ponto já superado pela doutrina constitucional brasileira" e afirmando que a intenção alegada do parlamentar relator da emenda de 1994 era "não de restringir a concessão da nacionalidade brasileira, e sim ampliar o direito à nacionalidade pelo critério do jus sanguinis". ${ }^{10}$ Francisco Guimarães também lamentava essa supressão: "O registro consular dispensava a opção, já que a nacionalidade surgia definitivamente com o registro que valia e ainda vale para os registrados até 09.06.1994, data em que entrou em vigor o texto constitucional revisado, como verdadeiro título de nacionalidade". ${ }^{11}$

9 Dolinger, Jacob, Direito internacional privado (parte geral), 5 ed., Rio de Janeiro, Renovar, 1997. Quadro sinóptico sobre a nacionalidade brasileira na evolução das Constituições, em apêndice.

10 Bernardes, Wilba Lúcia Maia, Da nacionalidade: brasileiros natos e naturalizados, Belo Horizonte, Del Rey, 1996, p. 150 (rodapé).

11 Guimarães, Francisco Xavier da Silva, Nacionalidade-aquisição, perda e reaquisição, Rio de Janeiro, Forense, 1995, p. 28. 
Alvissareira, nesse contexto, a Emenda Constitucional no. 54, de 20 de setembro de 2007, que deu nova redação à alínea $c$ do inciso I do artigo 12 da Constituição Federal de 1998. Por força desse dispositivo, são brasileiros natos "os nascidos no estrangeiro de pai brasileiro ou mãe brasileira, desde que sejam registrados em repartição brasileira competente ou venham a residir na República Federativa do Brasil e optem, em qualquer tempo, depois de atingida a maioridade, pela nacionalidade brasileira".

Essa alteração no texto constitucional veio, portanto, corrigir uma anomalia e ocorreu diante de uma realidade que beirava à perversidade. Estima-se que o número de brasileiros residentes em outros países chega a quatro milhões, cerca de um milhão deles nascidos após 1994. Essas crianças, muitas registradas em repartições brasileiras, não adimpliam - apesar do registro, que então lhes assegurava apenas efeitos de identificação civil- a condição de brasileiro, só possível com a residência no Brasil e opção pela nossa nacionalidade. ${ }^{12}$ Os países que abrigam maior número de brasileiros são Japão, Alemanha, Espanha, Itália, Portugal, Suíça e Suécia, e neles a nacionalidade é atribuída pelo critério do jus sanguinis, existindo o que a imprensa designa como "brasileirinhos apátridas", pessoas que não eram reconhecidas como nacionais pelo Estado em que nasceram e residem, nem como brasileiras, pela razão exposta.

Com a Emenda Constitucional no. 54, a aquisição de nossa nacionalidade pelo filho de brasileiro que nasce no estrangeiro fica facilitada, mediante o registro consular ou na embaixada, não necessitando ele vir ao Brasil para ser registrado, pois esse documento é fornecido pela repartição consular. Permanece válida a outra forma de alcançar a nacionalidade brasileira: vir residir no Brasil e optar pela condição de brasileiro, perante a justiça federal. Nesse caso, agora há clareza sobre o momento da opção: ela pode ser procedida, em qualquer tempo, desde que a pessoa tenha atingido a maioridade.

\section{A cidadania ao alcance dos brasileiros anacionais}

Conceito bastante amplo, ganhando a cada dia novos e significativos vieses, vamos identificar cidadania como o direito e o dever de todo ser humano de participar e intervir na organização e na vida do Estado, es- 
colhendo quem tem a incumbência de exercer todas as tarefas públicas e privadas, e podendo ser escolhido para esses encargos. Assume a cidadania hoje enorme importância e significado humano e social. E o direito fundamental à nacionalidade encontra-se, por certo, na base da cidadania, pois a pessoa sem nacionalidade fica excluída da maioria dos direitos e prerrogativas acessíveis aos demais seres humanos, incluindo o exercício do voto em eleições e outros processos de consulta popular.

Neste particular, faz-se pertinente estabelecer, mediante uma abordagem conceitual, a distinção entre nacionalidade, cidadania e direitos políticos. Por conseguinte, o instituto da nacionalidade, enquanto vínculo jurídico-político que une um ser humano a um Estado determinado, não se confunde com o instituto da cidadania, que expressa, em essência, a idéia de um nacional — nato ou naturalizado - no gozo de seus direitos políticos. Estes, por seu turno, também denominados direitos cívicos, conferem atributos de cidadania ao seu titular. Dessa forma, os direitos políticos encerram o direito e o dever de participação na organização do Estado, por intermédio do voto, em suas acepções ativa e passiva, bem como de outros mecanismos de consulta popular.

Ocorre, porém, que a cidadania não se esgota no exercício dos direitos políticos. Trata-se de um status, de um conceito amplo e dinâmico, que contém em seu âmago nuanças outras, as quais crescem em relevância no cenário contemporâneo. Nesse sentido, assumem peculiar relevo os vieses humano e social encerrados na idéia de cidadania, sobretudo, no atinente aos direitos das minorias, cujas reivindicações arrimam-se neste caráter não estanque e universal que caracteriza o cidadão no contexto atual.

Por sua pertinência, inserem-se observações, feitas há meio século, por Penna Marinho, ao encerrar seu longo estudo sobre o instituto que estamos identificando como anacionalidade:

Que se esforcem as legislações por suprimir as causas da apatria; que se limitem, nos casos de naturalização, os efeitos de perda da nacionalidade à pessoa naturalizada; que se facilitem às pessoas desnacionalizadas uma reaquisição rápida da cidadania perdida; que se prescrevam, nas anexações parciais, cláusulas de opção, impedindo a desnacionalização; que se estenda, nas anexações totais, a nacionalidade do estado anexante a todos os habitantes do território incorporado e que, por fim, se submetam os apátridas remanescentes à nacionalidade do país onde estão domiciliados, observa- 
das certas condições, e ter-se-á livrado os estados de um dos seus grandes flagelos. ${ }^{13}$

Como o reconhecimento da nacionalidade pelo registro consular cessara em 1994, estima-se que duzentos mil filhos de brasileiros, nascidos e residentes em outros países, os mencionados "brasileirinhos apátridas", permaneciam na condição de anacionais e alcançariam a maioridade - considerando-se a legislação brasileira - em 2012. Isso explica o amplo movimento pela aprovação do Projeto de Emenda Constitucional (PEC) 272/00, que redundou na Emenda no. 54/2007.

A Emenda Constitucional no. 54, de 20 de setembro de 2007, acrescenta, ainda, nas Disposições Constitucionais Transitórias, um novo artigo: "Artigo 95. Os nascidos no estrangeiro entre 07 de junho de 1994 e a data da promulgação desta Emenda Constitucional, filhos de pai brasileiro ou mãe brasileira, poderão ser registrados em repartição diplomática ou consular brasileira competente ou em ofício de registro, se vierem a residir na República Federativa do Brasil".

Convém destacar o zelo do revisor de 2007, com a inserção desse dispositivo, que assegura a todos os filhos de brasileiros nascidos em outro país, desde a supressão do registro em 1994 até a promulgação da Emenda no. 54, o direito de procederem a esse registro em repartição diplomática ou consular brasileira competente ou em ofício de registro, se vierem residir no Brasil. Dessa forma, a anacionalidade de filho de brasileiro nascido no estrangeiro passa a dispor de mecanismos legais amplos para a sua superação, integrando essas pessoas na comunhão nacional brasileira e colocando ao alcance das mesmas todos os direitos da cidadania.

\section{CONSIDERAÇÕES FINAIS}

Este estudo ocupou-se do instituto da nacionalidade, da anacionalidade e da Emenda Constitucional no. 54, de 20-09-2007, que reintegrou o registro consular na concessão da nacionalidade a filhos de brasileiros nascidos no estrangeiro.

13 Penna Marinho, Ilmar, Tratado sobre a nacionalidade, Rio de Janeiro, Departamento de Imprensa Nacional, vol. IV. 1956, pp. 330 y 331. 
Das reflexões aportadas neste estudo, infere-se que cidadania e nacionalidade, embora institutos distintos, são complementares, fundados em uma solidariedade de interesses e de sentimentos. Ambas se ocupam da pessoa física, o homem, que constitui a sociedade humana. Recordou-se que a ordem jurídica internacional admite dois critérios para normatizar a concessão da nacionalidade de origem: o jus sanguinis (pela filiação) e o jus soli (pelo local do nascimento). O Brasil privilegia o segundo, mas reconhece casos de jus sanguinis.

Foi proposto o uso do termo anacionalidade em lugar de apatridia, que, embora amplamente usado, porta forte viés estigmatizante, dando idéia de supressão do vínculo do ser humano com sua pátria. Anacional, menos contundente e mais brando, oferece conotação de transitoriedade a essa situação e leva ao entendimento de que a condição será passageira, pela inserção dessa pessoa entre os nacionais de um Estado.

A Emenda Constitucional no. 54 reintegrou à nossa ordem jurídica o registro consular como meio de concessão da nacionalidade brasileira, que fora suprimido por emenda anterior, de 1994. A condição de brasileiro nato pelo filho de brasileiro que nasce em outro país fica facilitada, mediante o registro em nosso consulado ou embaixada. Essa mudança coloca ao abrigo da nacionalidade brasileira cerca de duzentos mil menores, os "brasileirinhos apátridas", que permaneciam sem qualquer nacionalidade por terem nascido e residirem em Estados que adotam o critério do jus sanguinis.

Dessa forma, a anacionalidade de filho de brasileiro nascido no exterior passa a dispor de mecanismos legais amplos para sua supressão, assegurando a ele os direitos e prerrogativas das pessoas que viram a luz em nosso território.

\section{REFERÊNCIAS}

AKZIN, Mm. B. et al., La nacionalité dans la science sociale et dans le droit contemporain, París, Librairie du Recueil Sirey, 1933.

BACElar Gouveia, Jorge (Introdução), As Constituições dos Estados lusófonos, Lisboa, Aequitas, 1993.

BERNARDES, Wilba Lúcia Maia, Da Nacionalidade: brasileiros natos e naturalizados, Belo Horizonte, Del Rey, 1996.

DARDEAU DE CARVAlho, A., Nacionalidade e cidadania, Rio de Janeiro, Freitas Bastos, 1956. 
Del'Olmo, Florisbal de Souza, Curso de direito internacional público, 3 ed., Rio de Janeiro, Forense, 2008.

_ O Mercosul e a Nacionalidade: estudo à luz do direito internacional, Rio de Janeiro, Forense, 2001.

DOLINGER, Jacob, Direito internacional privado (parte geral), 5 ed., Rio de Janeiro, Renovar, 1997.

FARO JUNIOR, Luiz P. F. de, Direito internacional público, 4. ed., Rio de Janeiro, Borsoi, 1965.

FERRANTE, Miguel Jeronymo, Nacionalidade: brasileiros natos e naturalizados, 2. ed., São Paulo, Saraiva, 1984.

Silva Guimarães, Francisco Xavier da, Nacionalidade-aquisição, perda e reaquisição, Rio de Janeiro, Forense, 1995.

PENNA MARINHO, Ilmar, Tratado sobre a nacionalidade, Rio de Janeiro, Departamento de Imprensa Nacional, vol. I. 1956.

Web Site do Ministério da Justiça, disponível em http://www.mj.gov.br. Acesso em 20 de dezembro de 2007. 